\title{
A REVIEW OF ANALYSIS OF STRENGTH PROPERTIES OF CALCINED KAOLIN AND SILICA FUME
}

Jigyasa Shukla ${ }^{1}{ }^{\mathbb{W}}$, Professor Harsh Gupta ${ }^{2}$

${ }^{1}$ Research scholar, Department of Civil Engineering, Jawaharlal Nehru College of Technology, Rewa (M.P.), India

2 Professor, Department of Civil Engineering, Jawaharlal Nehru College of Technology, Rewa (M.P.), India

DOI: https://doi.org/10.29121/ijetmr.v7.i6.2020.721

Article Citation: Jigyasa Shukla, and Professor Harsh Gupta. (2020). A REVIEW OF ANALYSIS OF STRENGTH PROPERTIES OF CALCINED KAOLIN AND SILICA FUME. International Journal of Engineering Technologies and Management Research, 7(6), 160163.

https://doi.org/10.29121/ijetmr.v7 i6.2020.721

Published Date: 30 June 2020

Keywords:

Silica Fume

Durability

Compressive Strength

\section{ABSTRACT}

The Portland cement is very useful to construct the any structure in any shape and size. This is very important for concrete because of this is high cost material. The cement production has environmental problem during large scale production process. In this paper we are studying about Silica fume, durability and Compressive strength etc. The mix is very important for any construction using of some Calcined Kaolin, Sand and Aggregate.

\section{INTRODUCTION}

The cement is used in any construction and characterized as being hydraulic or non hydraulic, which is directly depend on the ability of cement using presence of water.

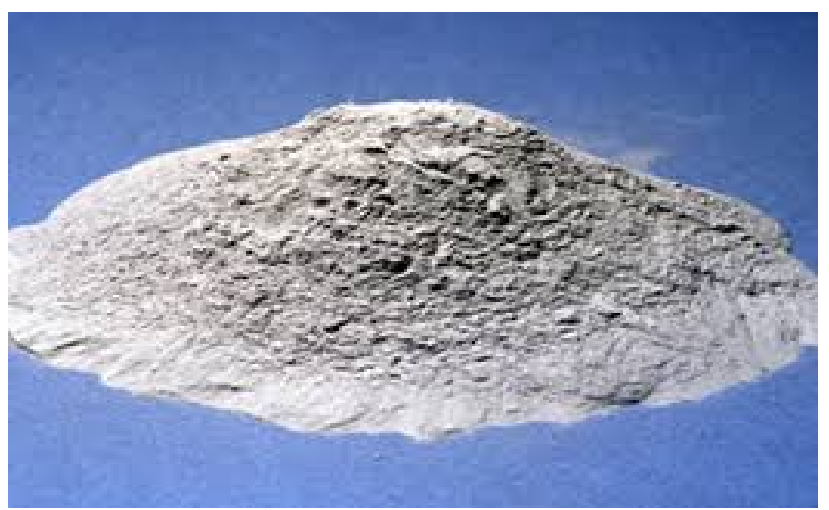

Figure 1: Cement

(C) 2020 The Author(s). This is an open access article distributed under the terms of the Creative Commons Attribution License, which permits unrestricted use, distribution, and reproduction in any medium, provided the original author and source are credited. 


\section{ADVANTAGES OF USING SILICA FUME}

- Compressive strength is high.

- Tensile, flexural strength and modulus of elasticity are high.

- Permeability to chloride is very low.

- Water intrusion is very low.

- Durability is enhanced

- Toughness is increased

\section{PORTLAND CEMENT}

This type of cement is also known as binding material, which is useful for any type structure and other needs. Different type of cement is prepared for different needs, this type of cement is very useful for any type of foundation.

\section{CALCINED KAOLIN}

Amorphous defect is formed at $980^{\circ} \mathrm{C}$ after this started the transformation with recrystallising when the temperature is above $1100^{\circ} \mathrm{C}$. During this process, a product is produced with this temperature range and provided the excellent properties in rubber component and improves the mechanical properties with chemical resistance

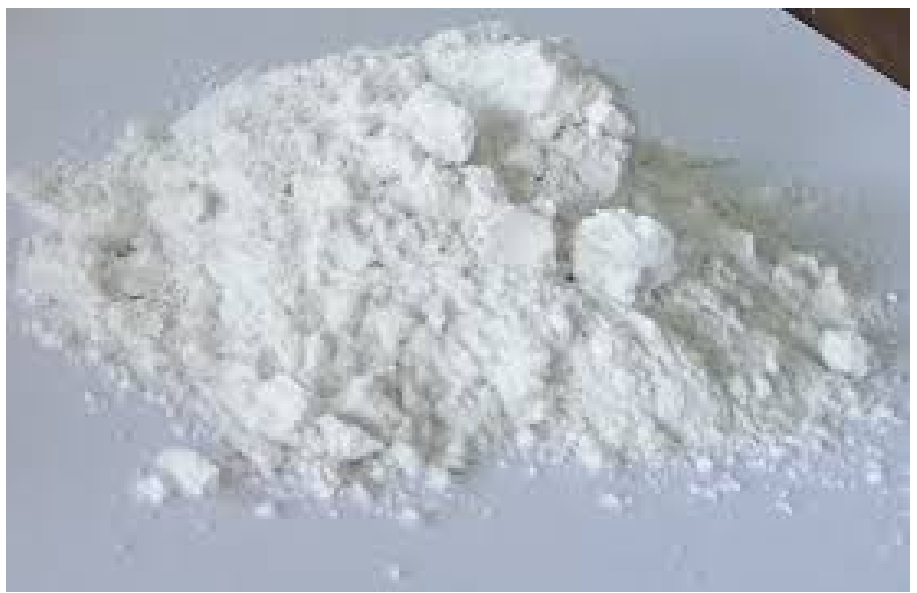

Figure 2: Calcined Kaolin

\section{SAND}

Composition of sand are varying which is depend on local rock sources and its condition.

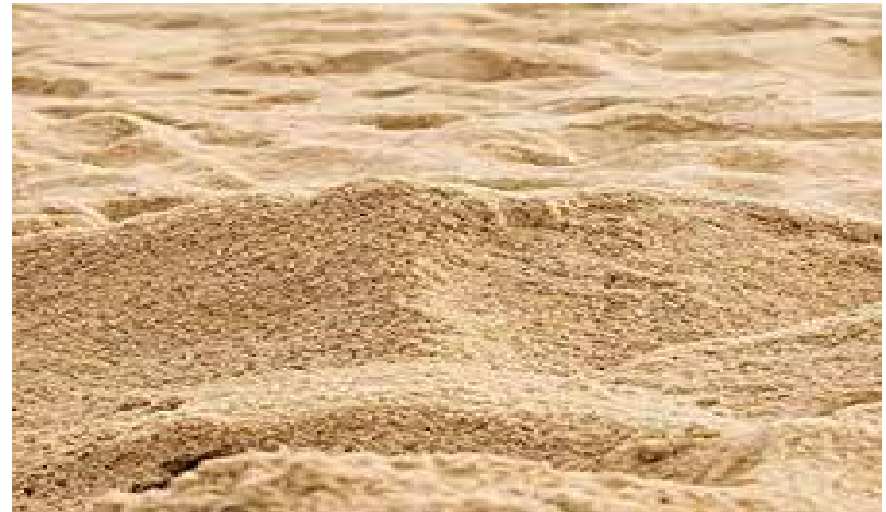

Figure 3: Sand 


\section{COMPOSITION}

Individual particle with range size is known as sand grain. The sand grain are varying between $2 \mathrm{~mm}$ to $64 \mathrm{~mm}$. silt is varying between $0.0625 \mathrm{~mm}$ down to $0.004 \mathrm{~mm}$.

\section{AGGREGATE}

The aggregate is work as reinforcement for increasing the strength in overall composite material. The aggregate is mostly used in foundation, french drain, wall drain and road side ending drain due to high hydraulic conductivity value. The aggregate is also used in any foundation and rail roads.

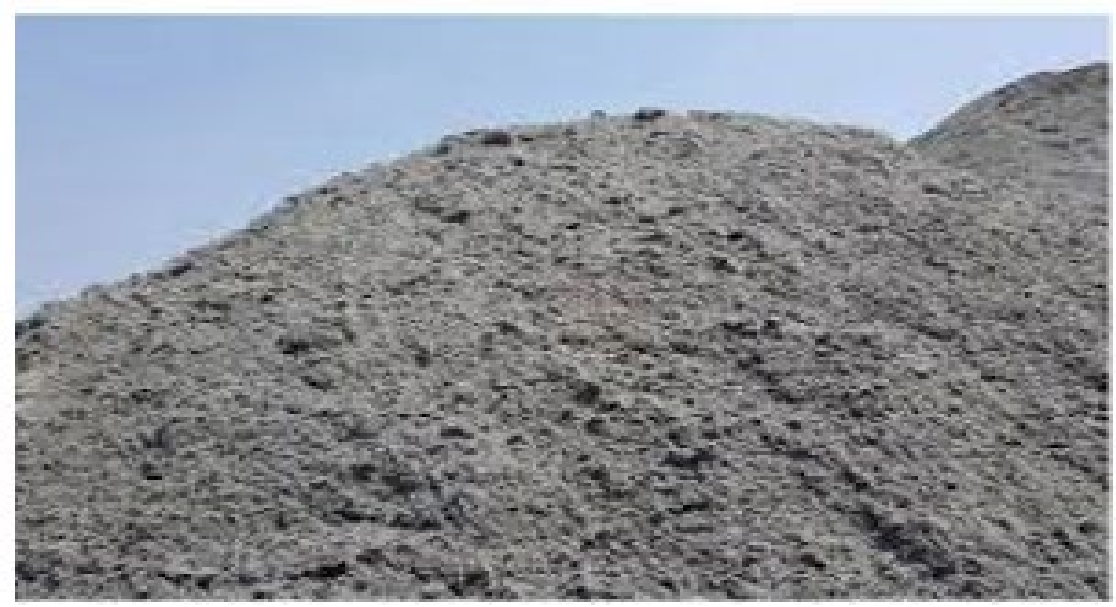

Figure 4: Aggregate

8. SILICA FUME

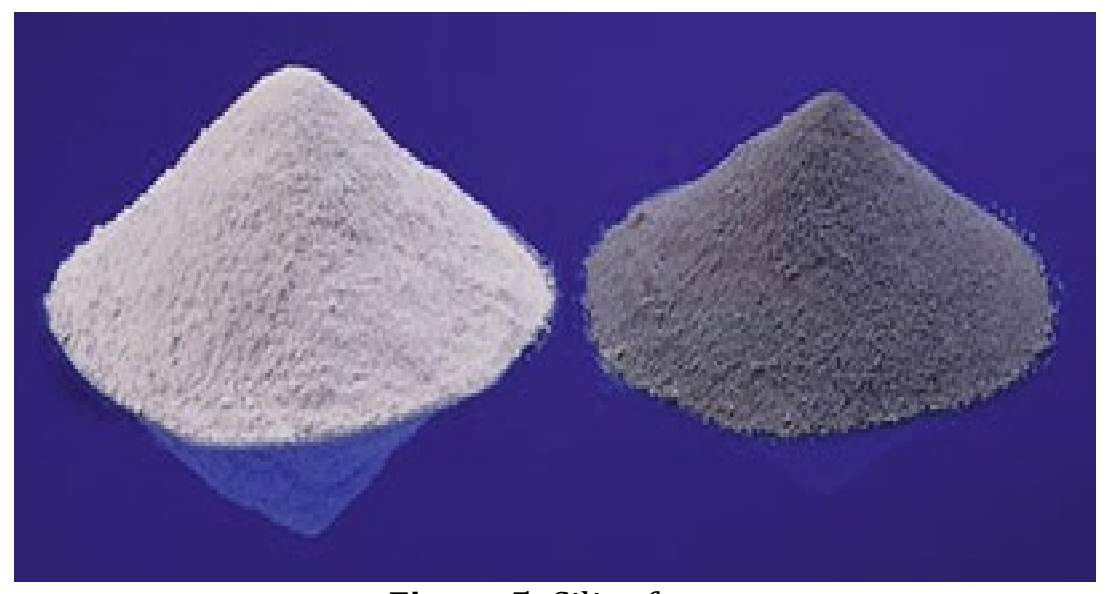

Figure 5: Silica fume

\section{CONCLUSIONS}

The workability of concrete are decreasing due to addition of Silica Fume and after this for increasing the workability of concrete to use of super plasticizers are very necessary. The water demand is decreasing in Silica Fume mixture.

\section{SOURCES OF FUNDING}

None. 


\section{CONFLICT OF INTEREST}

None.

\section{ACKNOWLEDGMENT}

None.

\section{REFERENCES}

[1] Biswas,S. "Mechanical properties and durability of rice husk ash concrete"(Report), International Journal of Applied Engineering Research December 1, 2008.

[2] Khedr, (1994) "Characteristics of Silica-Fume Concrete", Journal of Materials in Civil Engineering, ASCE 6 (3) 357 - 375.

[3] Zhou, Jing, (1993) "Properties of Silica Fume Concrete and Mortar”, ACI Materials Journal 90 (4) 349 - 356. 